\title{
El debate historiográfico sobre la Guerra de la Triple Alianza (1864-1870), la implicancia británica y la cuestión algodonera en el marco de la gestación del Estado nacional argentino
}

\author{
Esteban Chiaradía \\ Universidad de Buenos Aires, Argentina \\ chara.casilla@gmail.com
}

\section{Resumen}

El Estado argentino surgió en una espiral de violencia que condujo a un apocalíptico enfrentamiento: la Guerra de la Triple Alianza contra Paraguay (1864-1870). La misma fue objeto de una revisión por una pretendida nueva corriente historiográfica surgida tras la transición democrática en los países del Cono Sur y la caída del muro de Berlín como contexto. Esta "nueva" corriente encarna una reacción contra las lecturas revisionistas, particularmente aquellas que apuntaron a Gran Bretaña como instigadora de la guerra en su búsqueda de algodón barato para su industria textil afectada por la Guerra de Secesión norteamericana (1861-1865). En los últimos años algunos autores han sostenido que Inglaterra tuvo fuentes de provisión algodonera barata, abundante y cercana particularmente en Egipto- sin necesidad de fomentar una guerra fratricida en la cuenca del Plata, para concluir en una condena generalizada del revisionismo por simplista. Sin embargo, este juicio resulta también simplista, además de ser tributario de viejas taras de la historiografía tradicional liberal. En definitiva, al margen de la forma de abordar estos tópicos por las distintas corrientes y sus motivaciones políticas declaradas o subyacentes, la agenda de la injerencia británica en los conflictos bélicos del Cono Sur en la década de 1860 no está cerrada, y su reapertura resulta por demás interesante en la medida que hecha luz sobre el conflictivo proceso de gestación estatal argentino y su imposición sobre otros proyectos políticos y sociales en la región.

Palabras clave: Guerra de la Triple Alianza, algodón, historiografía, conformación del Estado nación.

\section{The historical debate about the War of the Triple Alliance (1864- 1870), the British implication and the cotton matter in the framework of the development in the Argentine National State}

\footnotetext{
Abstract

Argentine State emerged in a violent spiral of violence that leads to an apocalyptic confrontation: The War of the Triple Alliance against Paraguay (1864-1870). This was the target of a revision by an illusory new historiographic trend arisen after the democratic transition in the countries of the
} 
Southern Cone (1864-1870) and the fall of the Berlin Wall as a context. This 'new' trend embodies a reaction against revisionist readings, particularly those that pointed to Great Britain as an instigator of the War in its search for cheap cotton for its textile industry affected by the American Civil War (1861-1865). In recent years some authors have claimed that England has sources of cheap, abundant and close cotton supply-particularly in Egypt- without the need to foment a fratricidal war in River Plate basin, to conclude in a generalized condemnation of revisionism as simplistic. However, this judgement is also simplistic as well as being tributary of old obstacles of the traditional liberal historiography. In short, outside the way these issues are addressed by the different trends and their declared or underlying political motivations, the agenda of British interference in the conflict of the Southern Cone in the 1860s is not closed and its reopening is also interesting because it simplifies the conflictive process of the Argentinean Government and its imposition on other political and social projects in the region.

Key Words: Word of the Triple Alliance, cotton, historiography, framework of the nation state.

Cada 25 de mayo se celebra en las escuelas argentinas un aniversario de la Revolución de Mayo de 1810, fecha donde comenzaría -según ciertas versiones nacionalistas- la "patria" argentina. Sin embargo, cada 9 de julio se celebra también en las escuelas la independencia argentina proclamadaenelCongresode Tucumán de 1816. Dos fechas para el "cumpleaños de la patria". La situación puede ser embarazosa para los profesores de historia que intentan dar cuenta del proceso de gestación del Estado argentino. Particularmente dado que ni en 1810 ni en 1816 tenemos un Estado argentino como tal, sino una entidad política previa y conflictiva: las Provincias Unidas del Río de la Plata. ¿Cómo se convirtieron estas Provincias Unidas en la República Argentina? Es un largo relato donde la violencia y los crímenes de guerra tienen mucho para decir. Pero fundamentalmente los historiadores ("profesionales" o no) han dicho mucho al respecto.

Este artículo trata de algunas de las interpretaciones en torno a un proceso bélico fundamental para la conformación del Estado argentino, y su derrotero en los últimos tiempos historiográficos, volviendo a replantear temas que la corporación historiográfica consideraba como superados, aunque nunca debatidos.

\section{La guerra en su momento histórico}

El proceso de gestación del Estado nacional argentino, como ocurriera en la mayor parte de los casos latinoamericanos, se vio inmerso en cruentas guerras civiles. Pero en la cuenca del Plata esta situación dio lugar a una espiral de violencia a partir de la batalla de Pavón $(1861)^{1}$, cuyo trágico pináculo fue la Guerra de la Triple Alianza contra Paraguay (18641870), el mayor conflicto bélico entre repúblicas hispanoamericanas y una de las cuatro mayores guerras del mundo decimonónico ${ }^{2}$, que enfrentó a la Triple Alianza del Imperio de Brasil y las repúblicas de Argentina y Uruguay contra la República del Paraguay.

Esta guerra se encadena con la crisis oriental originada en abril de 1863 con la invasión desde Buenos Aires del "colorado" uruguayo Venancio Flores contra el gobierno oriental del Partido Blanco. Frente a esta situación, Paraguay declaró

1 En esa batalla de desarrollo militar confuso el separatista Estado de Buenos Aires, con Bartolomé Mitre como referente, se impuso sobre la Confederación Argentina presidida por el cordobés Santiago Derqui bajo la égida de Justo José de Urquiza, caudillo de la provincia de Entre Ríos. Comienza así un proceso de centralización política en torno a la oligarquía de Buenos Aires, que en forma inmediata inició una "guerra de policía" contra las provincias, particularmente contra el general Vicente Ángel Peñaloza, a quien asesina salvajemente.

2 HOBSBAWM, Eric. La era del capital (1848-1875). Buenos Aires: Crítica, 2010 [1975], pp. 88, 89 y 152. 
casus belli una posible intervención brasileña en los asuntos uruguayos ya que desde la apertura a la navegación internacional del río Paraná su comercio exterior se realizaba por el puerto de Montevideo, a la par que crecían los conflictos con Buenos Aires y Río de Janeiro. La invasión imperial a Uruguay, el 12 de octubre de 1864, inició la fatídica Guerra Guasú ${ }^{3}$.

A continuación, Paraguay tomó la iniciativa al norte en Mato Grosso (Brasil), y luego al sur con la ocupación de Corrientes (Argentina) y el litoral fluvial de Río Grande do Sul (Brasil). En una segunda fase los aliados recuperaron Uruguayana y Corrientes, y posteriormente comenzó el largo asedio a las fortificaciones paraguayas, estancándose la guerra frente a Humaitá y Curupayty. Tras la toma y saqueo de Asunción (1869) el conflicto se convirtió claramente en una guerra de exterminio del pueblo paraguayo y de destrucción sistemática de su infraestructura hasta la batalla final de Cerro Corá (1870) allí muere el presidente paraguayo Francisco Solano López y concluye la guerra, dejando un Paraguay asolado y a los aliados enfrentando deudas por el esfuerzo bélico, situación que fue sumamente benéfica para los capitales británicos interesados en hacer negocio con la tragedia de esta región.

En Argentina la guerra fue sumamente impopular, generándosediversoslevantamientos armados contra el gobierno central ${ }^{4}$, desbandes de tropas, manifestaciones públicas de disidencia censuradas por el gobierno ${ }^{5}$ e incluso casos de argentinos que se sumaron al ejército paraguayo ${ }^{6}$.

Más allá de la simpatía o no con el estilo del gobierno paraguayo, la coyuntura política internacional y el cada vez más evidente carácter de exterminio de la acción aliada llevó a que las demás repúblicas hispanoamericanas, en especial al hacerse público el contenido secreto del Tratado de la Triple Alianza, se mostraran contrarias a esta guerra, rechazando la alianza de dos repúblicas con un imperio esclavista en momentos en que en México Benito Juárez llamaba a expulsar al emperador-usurpador Maximiliano de Austria (primo del emperador brasileño), mientras el pueblo dominicano luchaba contra la segunda dominación española y las repúblicas del Pacífico sellaban una alianza defensiva contra la bárbara intervención militar española a partir del episodio de las islas Chincha. Algunos gobiernos realizaron gestiones para lograr la paz (rechazada por los aliados), otros -como el colombiano- ofrecieron su ciudadanía a los paraguayos en caso que los aliados impusieran la desaparición del Paraguay como entidad soberana (Chiaradía, 2015).

Esta ola de simpatía americanista tenía su contracara en la actitud del gobierno de Buenos

3 "Guerra Grande", en guaraní; denominación habitual en Paraguay para la guerra con la Triple Alianza. Para estos sucesos previos, entre otros: CÁRCANO, Ramón J. (1939). La Guerra del Paraguay. Orígenes y causas. Buenos Aires: Domingo Viau. CHIAVENATO, Julio José. Genocidio Americano. La Guerra del Paraguay. Asunción: Carlos Schauman Editor, 1989. DORATIOTO, Francisco. Maldita guerra. Nueva historia de la Guerra del Paraguay. Buenos Aires: Emece, 2008. GUERRA VILABOY, Sergio. Paraguay: de la independencia a la dominación imperialista: 1811-1870. Asunción: Carlos Shaumann Editor, 1991. HERRERA, Luis Alberto de. El drama del '65: la culpa mitrista. Montevideo: Cámara de Representantes, 1990. POMER, León. La Guerra del Paraguay. Estado, política y negocios. Buenos Aires: Centro Editor de América Latina, 1968. NABUCO, Joaquín. La Guerra del Paraguay. París: Garnier Hermanos, 1901. ROSA, José María. La Guerra del Paraguay y las montoneras argentinas. Buenos Aires: Hyspamérica, 1985. TEIXEIRA, Fabiano Barcellos. A Primeira Guerra do Paraguai. A expediçao naval do Império do Brasil a Assunçao (1854-5). Passo Fundo: Méritos, 2012. WHIGHAM, Thomas. La Guerra de la Triple Alianza. Taurus, Asunción, 2011.

4 Como el liderado por Felipe Varela bajo la consigna de la Unión Americana.

5 Los intelectuales más destacados en su militancia antibélica fueron Juan Bautista Alberdi, Carlos Guido y Spano, Miguel Navarro Viola y Olegario Víctor Andrade. El gobierno de Mitre declaró el estado de sitio, clausuró periódicos opositores y obligó a exiliarse a varios disidentes.

6 El caso mas sonado fue el del coronel Telmo López, hijo del histórico caudillo de la provincia de Santa Fe, Estanislao López. 
Aires. Al referirse a la invitación a participar en los congresos americanos y suscribir los tratados surgidos de los mismos bajo la premisa de la unidad frente a la amenaza colonialista europea, el presidente Mitre justificó las correrías del empresario y delincuente norteamericano William Walker en Centroamérica y despreciando cualquier acercamiento con las demás repúblicas hispanoamericanas:

Una de las bases fundamentales de la política argentina es no tomar parte en ningún Congreso Americano como el que se ha reunido en Lima; la primera idea de esto fue hija de una idea antiamericana, una liga contra los Estados Unidos con motivo de Walker, es decir una liga contra el campeón de la democracia en el mundo y la égida de la América del Sud contra los avances de Europa. [...]. Era tiempo ya de que abandonásemos esa mentira pueril de que éramos hermanitos y que como tales debíamos auxiliarnos, enajenando recíprocamente parte de nuestra soberanía. (Mitre, cit. en Morgenfeld 2011: 29)

\section{La guerra en el desarrollo historiográfico}

Más allá del escenario bélico histórico (18641870), en el cual se desplegó el enfrentamiento político-militar entre proyectos de desarrollo antagónicos, la guerra se prolongó en otro escenariobélicosimbólico(1864ycontinúa), encuyo frente historiográfico siguieron debatiéndose las ideas-fuerza de diversas tradiciones, grosso modo, la liberal y la revisionista. La posición liberal, mitrista, enfatizó en una explicación patológica del conflicto: todo se debía a la locura de Solano López, obligando a la Argentina a firmar una alianza para llevar la civilización y el progreso al pueblo paraguayo víctima de un tirano desalmado. Los opositores de entonces rebatieron y ridiculizaron esta explicación, pero su voz fue acallada. En la segunda mitad del siglo XX la corriente revisionista formuló sus mejores obras, en sus variantes nacionalistas o marxistas. Enrique Rivera (1954) introdujo la idea de complicidad británica con los aliados, tema que aparece menos evidente en José María Rosa (1958-1959), quien sin embargo aporta datos interesantes sobre el accionar diplomático británico en el período. Pero será recién en 1968 con la obra de León Pomer sobre la guerra cuando se analice con mayor detenimiento el rol de Gran Bretaña en el conflicto. Pomer ubicó la guerra en un contexto mundial del desarrollo capitalista, postulando que la guerra civil norteamericana limitó la provisión de algodón a la industria textil británica, conduciendo a aquel imperio a buscar fuentes alternativas. En ese plano insertó Pomer el juego británico en el Plata.

Por otra parte, en Cinco años de guerra civil en Argentina (1865-1870), Pomer (1985) abordó la instauración del poder estatal mediante una guerra interna desatada sobre la población a la par que la guerra externa contra el Paraguay. Es decir, desnudó el carácter violento extremo de dicho proceso de conformación del Estado nación.

Las investigaciones de Pomer encontraron eco en Brasil, en la popular obra del periodista Julio José Chiavenato, Genocidio americano, aparecida en 1979. Sin embargo, en Argentina no corrió con igual suerte. La fracción historiográfica que ganó terreno desde fines de la dictadura cívicomilitar (1976-1983) y la transición democrática no le prestó atención al análisis de esta guerra, limitándose a repetir fórmulas tradicionales del mitrismo y condenando a priori cualquier aporte desde el revisionismo y el marxismo ${ }^{7}$. Las pocas obras argentinas sobre la guerra reiteraron los términos que definieron las corrientes historiográficas en pugna décadas atrás. El tema parecía estar congelado. Pero esa situación estaba cambiando, particularmente en tierras de un antiguo aliado.

7 Incluso una figura clave en la articulación de las redes corporativas historiográficas como Luis Alberto Romero (1996: 93-94) manifestaba alivio y cierto beneplácito por la sangrienta represión dictatorial que sufrieran los historiadores marxistas y revisionistas. Este mismo Romero lidera hoy el coro negacionista que intenta justificar al terrorismo de Estado de la última dictadura impuesta a los argentinos. Véase: http://www. politicargentina.com/notas/201601/11120-un-intelectual-de-cambiemos-le-pidio-a-macri-que-termine-conlos-juicios-contra-los-represores.html 
Desde la caída del muro de Berlín, el retorno ala democracia en el ConoSur y la profesionalización universitaria, fue muy festejada una renovación temática y metodológica en el abordaje de la Guerra de la Triple Alianza contra Paraguay que puso énfasis en ciertos tópicos (historia de género, de la cultura, de la prensa, etc.) si bien descuidó -en muchos casos- una visión holística o dejó de lado -sin resolverlos- aspectos que hasta entonces eran de relevancia en el debate.

Ya en los años ochenta comienza en Brasil lo que Francisco Doratioto designó pomposamente como "Interpretação Sistêmica Regional" (2008, 2009), Liliana Brezzo llamó “Nueva historiografía sobre la guerra de la Triple Alianza" (2003: 158), Thiago Rabelo Sales calificó de "neorevisionismo" (2008) y Mário Maestri con una mirada crítica- denominó "Restauração historiográfica" (2009: 16), caracterización esta última con la que coincidimos y adoptamos.

La aparición de $O$ expansionismo brasileiro de Moniz Bandeira (1985) se suele considerar como el punto de arranque de esta nueva etapa historiográfica brasileña sobre la guerra, afirmación que merecería mayor análisis. Esta tendencia continuó con A Guerra do Paraguai: escravidão e cidadania na formação do Exército de Ricardo Salles (1990). Otra de las figuras que destaca en este período es Alfredo Da Mota Menezes, para quien la guerra fue construida por el imperio del Brasil, otorgando gran importancia a la situación oriental platina y negando rotundamente la injerencia británica en la misma.

Los 130 años del inicio de la guerra, en 1994, fueron motivo en Brasil de una puesta en limpio de las producciones recientes mediante un seminario y una posterior publicación, bajo el patrocinio del Banco Real y la Fundación Roberto Marinho (el dueño del pulpo mediático Red Globo). Contó con la presencia estelar de Leslie Bethell, quien se despachó contra la tesis del imperialismo británico en América Latina (reclamó que no lo usen como chivo expiatorio), volviendo a las interpretaciones decimonónicas de la guerra: el tirano desquiciado Solano López (Bethell 1995).

Pero la obra emblemática y realmente fundadora de esta pretendida renovación historiográfica restauracionista, celebrada incluso en medios militares como un arma contra el comunismo, es la voluminosa Maldita guerra (aparecida en 2002) de Francisco Doratioto, donde se intentó tomar distancia de las dos corrientes dominantes en las interpretaciones de la guerra. Sin embargo, no ocultó su afinidad con la corriente liberal tradicional:

La generación de aquellos que lucharon en la guerra, en los países aliados o en Paraguay, no consideraba de manera positiva el papel histórico de Solano López. Existía la certeza sobre su responsabilidad, sea en el desencadenamiento de la guerra, al invadir Mato Grosso, sean en la destrucción de su país [...] De esta generación nació la historiografía tradicional sobre la guerra, la cual simplificó la explicación del conflicto ateniéndose a las características personales de Solano López, caracterizado como ambicioso, tiránico y aun como casi desequilibrado. Esa caracterización no estaba lejos de la realidad y hasta puede explicar ciertos mementos de la guerra, pero no su origen y su dinámica. (Doratioto, 2008: 16-17)

Es decir que la visión de Solano López como tirano desquiciado mantiene cierto valor explicatorio. A continuación, Maldita guerra renovó las comparaciones despreciativas del presidente paraguayo (de Napoleón, Nerón, Calígula, Atila y César Borgia pasamos con Doratioto a Hitler, Stalin y Stroessner) y los presupuestos del liberalismo historiográfico eran aggiornados mediante la comparación con el nazismo (2008: 433). Así, la guerra respondió a la necesidad paraguaya de buscar la realización de su Lebensraum (2008: 39) ${ }^{8}$ y retomó el concepto de Blitzkrieg para calificar las campañas paraguayas de 1864-65 (2008: 454-455).

8 El espacio vital disputado a otros estados que postuló Friedrich Ratzel en la Alemania bismarckiana, y que sustenta la estrategia militar nazi con Karl Ernst Haushofer como ideólogo. 
Esta nueva historiografía postulada por Doratioto atribuyó al revisionismo una marcada influencia del contexto de época, signado por la lucha contra las dictaduras latinoamericanas de los tiempos de la "guerra fría" -y el consecuente ataque al pensamiento liberal ligado a aquellas-, y por el antiimperialismo que hace necesario apelar a Gran Bretaña para explicar el exterminio de lo que se veía como un modelo autónomo de desarrollo paraguayo. Por el contrario, la "nueva historiografía" se caracterizaría por el mayor peso de las fuentes primarias (independientemente del tratamiento que de las mismas se haga) y, en base a ello, la postulación de los orígenes de la guerra en un proceso histórico regional que prescinde de la acción de Gran Bretaña, se esfuerza en presentar al Brasil como sujeto autónomo en el contexto internacional $\mathrm{y}$, consecuentemente, necesita como piedra angular de su interpretación un Paraguay despótico, atrasado y con deseos expansionistas, revés de trama del civilizado imperio esclavista y liberal de Pedro II.

\section{Algodón, imperio y guerra ${ }^{9}$}

El estrecho vínculo entre la industrialización británica y el comercio colonial ha sido abordado por diversos especialistas. $\mathrm{Y}$ muchas de las guerras de este período estuvieron atravesadas por las necesidades de dicha industrialización imperial.

Desde fines de la década de 1950 en adelante, un sector del revisionismo ha planteado que los intereses capitalistas británicos durante el siglo XIX tuvieron un rol significativo (pero no discrecional) en la destrucción de procesos autocentrados o autónomos de desarrollo nacional. En relación a la Guerra de la Triple Alianza, este planteo se inicia a mediados de la década de 1950 con Enrique Rivera (1954), Rául Scalabrini Ortíz (1956), José María Rosa (1958-59, 1965), autores "dependentistas" como José Alfredo Fornos Peñalba (1979) o Sergio Guerra Vilaboy (1984) y también está presente en Vivián Trías (1975), Eduardo Galeano (1971) y Oscar Creydt (1963), entre otros. A fines de los sesenta se agrega un giro en esta interpretación: la injerencia británica tuvo por móvil el hacerse con tierras y materias primas como el algodón en el contexto de la guerra civil de EEUU y las necesidades británicas de abastecimiento a la industria textil de Lancashire (León Pomer 1968, José Chiavenato, 1989). En los setenta se aportó otro elemento: la incidencia de las necesidades de la industria textil de EEUU incrementando la necesidad británica de algodón (Rodolfo Ortega Peña y Luis Eduardo Duhalde, 1975).

Por otra parte, la tendencia historiográfica liberal continuó negando la injerencia del "imperialismo" británico al tiempo que otorgó mayor peso a los factores internos, pero escindiéndolos del contexto mundial. Esta perspectiva presentó al Paraguay francista y lopizta (1812-1870) como un estereotipo de aislamiento irracional. Para esta ratio liberal cualquier ideal de desarrollo autonómico fue homologado con una especie de absurda renuncia a la lógica benéfica de la apertura política, económica, demográfica y cultural hacia la Europa noroccidental "civilizada".

Partiendo de este supuesto, los historiadores liberales visualizaron como positivas las inversiones de capital extranjero que, si bien se dieron a lo largo del siglo XIX, incrementaron notablemente su valor durante el último tercio de la centuria. Gran Bretaña apareció como una suerte de "promotor" del desarrollo capitalista latinoamericano, por tanto no resulta extraño que desde una perspectiva liberal se niegue $o$ desdeñe la presencia que los capitales y la política británica tuvieron en el origen, desarrollo y desenlace de conflictos como la Guerra Guasú o la Guerra del Pacífico, tal como sostiene Tate (2003) y Bethell (1995). Consecuente con dicha línea, el historiador brasileño Alfredo da Mota Menezes sostuvo en su obra A guerra é nossa: a Inglaterra não provocou a Guerra do Paraguai:

A intenção deste livro é trazer dados e informações que mostrem que os ingleses não

9 En este apartado retomamos conceptos trabajados en CHIARADÍA, Esteban y SACCO, Claudio, 2014. 
criaram o maior confronto armado da América do Sul. Essa ideia é ainda forte no nosso continente e se buscam mais dados e fatos para provar o contrário (Menezes, 2012: 8).

Si bien este autor reconoció que importantes intelectuales como Eric Hobsbawm y André Gunder Frank defendieron la tesis de cierta responsabilidad del expansionismo del capital británico para el inicio de una guerra fratricida sudamericana, él propone que la racionalidad histórica del conflicto pasó por otro lado. Esta visión es coincidente con la expuesta por Francisco Doratioto, para quien la guerra se explicaría por razones de índole puramente regionales (en su mayoría ligadas con reclamos que dirigían al gobierno imperial brasileño los grandes hacendados riograndenses que operaban económicamente en el norte de Uruguay).

En síntesis, el núcleo de las tesis de autores de la "nueva ola" historiográfica como Menezes y Doratioto presentó a la guerra como resultado de problemas regionales que estaban desconectados de una totalidad internacional en momentos de expansión capitalista.

Finalmente, Doratioto intentó negar la injerencia de Gran Bretaña señalando que el mercado paraguayo era diminuto, que la guerra civil norteamericana ya había finalizado, que Gran Bretaña se proveyó de algodón egipcio y, fundamentalmente, que el diplomático Edward Thornton había ofrecido -a título individualsus buenos oficios para evitar la guerra. Cada uno de estos argumentos merecería ser tratado en profundidad. Sin embargo, hemos decidido someter a crítica su posición respecto del algodón egipcio -único argumento que remite a una mirada conectada con la totalidad internacional- pues consideramos que Doratioto no logra falsear la tesis revisionista, en razón de lo cual la conexión del algodón con la Guerra Guasú continúa siendo materia para el debate historiográfico. Remitiéndonos a un pasaje de su Maldita Guerra podemos leer:

En cuanto al algodón, la Guerra del Paraguay comenzó cuando ya había terminado la lucha norteamericana, $\sin$ que en el lapso de ese conflicto Gran Bretaña hubiese encarado cualquier iniciativa para obtener algodón paraguayo. Además, desde 1860, las necesidades de la industria textil británica estaban cubiertas por la compra de algodón en Egipto. (Doratioto, 2008: 81)

La última oración no es retomada para profundizar y documentar en una obra que ronda las seiscientas páginas. Sin embargo, se ha convertido para muchos historiadores del medio local en una suerte de "fallo inapelable" que borra de un plumazo todo intento de vincular intereses británicos con esta guerra. Numerosos historiadores argentinos se aferraron a esta afirmación apresurada y sin fundamentos pero respaldada por el prestigio corporativo profesional para saldar cuentas con las críticas levantadas por el revisionismo y el marxismo contra la interpretación oficial de la guerra en Argentina y de la conformación del Estado nación argentino.

La oración citada amerita indagar en el país de las pirámides que colmará el hambre algodonero de la Inglaterra victoriana. Para ello, resulta oportuno conocer la "vía egipcia" a la modernización y las dificultades en que se vio envuelta la política imperial y capitalista de Gran Bretaña en esas latitudes. Y más aún, conocer cuán pertinaz resultó ser la oposición del imperio británico al proceso de desarrollo autocentrado de Egipto.

Una mejor comprensión de estas cuestiones acaso vuelva menos "fabulosa" la hipótesis de que agentes comerciales del Imperio, en un contexto internacional de crisis para el mercado primario algodonero (1861-1865), se hayan visto obligados de llevar sus pies a la lejana tierra guaraní.

Podemos destacar dos procesos de modernización en Egipto: uno de carácter autonómico con Mehmet Ali (1805-48), otro de carácter dependiente -no exento de sobresaltoscon Mehmet Said (1854-63) e Ismail (186379). Egipto era la más rica de las provincias otomanas: buena agricultura y recaudación tributaria, control del comercio del Mar Rojo hacia la Meca y la India (Rogan, 2010). El sultán 
delegó el gobierno en la despótica y odiada elite extranjera de los mamelucos en un contexto internacional en el que la provincia era codiciada por Inglaterra, Francia y Rusia.

La aventura militar de Napoleón en Egipto (1798-1801) fue derrotada por una alianza anglo-turca y sobrevino un vacío de poder. Pero recostándose en los notables locales y los sectores populares, un albanés que integraba las tropas otomanas de reconquista, Mehmet Ali, consiguió ser nombrado wali (gobernador), frustrando así los planes británicos-que pretendían un gobierno indirecto con los mamelucos- aplastando la invasión inglesa de 1807. Comenzó una lenta desotomanización que para muchos autores es el comienzo del estado egipcio moderno y de la “egipcianidad" (Marsot, 1984 y 2007).

El wali comprendía la necesidad de un plan de modernización con elEstadocumpliendola función de acumulación primitiva (Amín, 1972), así que emprendió una "reforma agraria" expropiando a los mamelucos y confiscando tierras de carácter religioso para repartir parcelas a los campesinos nativos (Quintana Pali, 1981), mientras emprendía conquistas militares (Arabia, Sudán, Gran Siria, Peloponeso, Creta) que aseguraban rutas, materias primas, mano de obra, impuestos y mercados para los productos egipcios.

El arreglo de los campos permitió a Ali organizar desde el Estado la producción de cultivos exportables a gran escala (algodón, índigo, trigo, arroz, sésamo, legumbres), y también ordenó concentrar la actividad artesanal -textil y otras- en talleres estatales, al tiempo que desarrolló algunas industrias (siderúrgica, química, naval, curtiembres, etc.). Financió la experimentación agrícola que logró el algodón Jumel de fibra larga, sin duda el de mejor calidad a nivel mundial y que habría de convertirse en un símbolo del Egipto moderno (Azzaola, 2008). Pero rechazó los planes de los técnicos europeos para construir ferrocarriles y abrir un canal en el istmo de Suez por considerarlas propuestas sólo benéficas al interés británico.

El algodón claramente terminó por desplazar a los otros rubros exportables, aunque los ingresos nacionales descansaron en gran medida sobre la recaudación fiscal agraria. Pese al monopolio, las tarifas aduaneras y la mano de obra barata los productos egipcios continuaron siendo caros aunque pudieran ser colocados en los territorios conquistados y en otras provincias otomanas, desplazando así a los textiles palestinos, sirios e indios y -en menor grado- ingleses. Dicha colocación generaba la cólera de Inglaterra, claro indicativo de la potencialidad de estas industrias para ganar o disputar mercados a los europeos, en especial en el rubro algodonero (Marsot, 1984 y 2007).

Sin embargo, este desarrollo fue truncado por la capitulación otomana de Balta Liman (1838) que impuso la apertura comercial para las manufacturas británicas y la prohibición a las provincias de fijar monopolios. Egipto se negó a aceptarlo y proclamó su independencia, cerrando el paso del istmo de Suez a los ingleses y aplastando al ejército otomano. Pero la alianza militar de las potencias con el sultán se impuso: Egipto perdió la flota, debió reducir su ejército y abandonar gran parte de sus conquistas territoriales (Fargette, 1996).

La derrota externa, retroalimentada por factores negativos de orden interno, redujo la escala de la producción y asestó un golpe mortal al modelo de desarrollo autonómico. La necesidad de contar con excedentes exportables transformó a la clase dirigente: de ser una burocracia "mandarina" se convirtió en latifundista, orgánicamente vinculada al capital extranjero (Quintana Pali, 1981: 449, Amin, 1972: 39-41).

Con el nuevo wali, Mehmet Said, comenzará la integración de Egipto en forma dependiente a la economía mundial. La década de 1860, signada por la coyuntura favorable de la Guerra de Secesión Norteamericana (1861-1865), vio trepar al $70 \%$ los ingresos egipcios por la exportación de algodón, creciendo también la exportación de semilla de algodón. Al término de la guerra el precio del algodón bajó, si bien mantuvo un nivel superior al de los años previos a la guerra, mientras los productores incrementaban la superficie cultivada (Quintana Pali, 1981: 445446). 
Por otro lado, el estimulo de los altos precios no condujo a Said a intervenir en la producción, muy a pesar de las presiones de la Manchester Cotton Supply Association para que acepte capital británico tendente a asistir a los cultivadores; se recurrió a usureros locales antes que a la banca internacional. Asimismo, al margen de algunas desmotadoras de vapor, el estado no alentó la introducción masiva de mejoras técnicas sino que recurrió a la expansión de la superficie cultivada (Quintana Pali, 1981).

Otro aspecto a considerar es que las hilanderías inglesas no podían aprovechar a pleno el algodón egipcio de mejor calidad (de fibra larga). El perfeccionamiento tecnológico que creó un sector dedicado a la transformación de las fibras largas (proceso de mercerización) llegará recién a fin del siglo XIX.

En 1854 Said otorgó al diplomático francés Ferdinand de Lesseps la concesión para construir un canal en Suez. Lord Palmerston se opuso, dado que el canal separaría a Egipto de Istanbul y caería en manos de Francia. Pero muy a su pesar, en 1859 la Compañía Internacional del Canal inició las obras utilizando mano de obra campesina provista por el gobierno egipcio en cuotas mensuales como parte del contrato. Esta corvée consumía mensualmente el trabajo vivo de 20.000 campesinos, los cuales permanecían fuera de sus hogares más de tres meses. Esto nos da una movilización hacia el istmo de 240.000 campesinos al año, pero la merma en los campos de algodón es de más de 720.000 hombres al año, en un país con una población de unos seis millones de habitantes. Además, otras obras vinculadas al canal demandaron abundante mano de obra adicional: un canal de agua dulce desde el Nilo para combatir la disentería y el cólera, y un puerto y ciudad en una playa poco profunda y de arenas movedizas en el Mediterráneo, Port Said.

Todas estas obras disputaron mucha fuerza de trabajo a la producción algodonera. Inglaterra denunció la corvea y presionó a Istanbul y El Cairo para que la Compañía utilizara tecnología, reduciendo así los contingentes campesinos en el canal. En 1864, la Compañía encargó dragas y otras maquinarias. Así y todo, en 1865 el descenso de mano de obra no fue automático, ya que fue requerida en parte para montar las instalaciones de las maquinarias (Headrick, 1998: 135-136).

Al término de las obras, Istanbul y Londres abandonaron su oposición al canal mientras la diplomacia inglesa procuró garantizar la neutralidad de la zona y en paralelo la banca Rothschild movió sus fichas allí. El 17 de noviembre de 1869, en una pomposa ceremonia con champaña, discursos y monarcas europeos, se inauguró el canal construido con capital francés y sangre egipcia para la gloria de Inglaterra. Ismail, sucesor de Said, creyó que así Egipto era parte de Europa. Las obras fastuosas y el derroche de su gobierno llevaron a la bancarrota, entonces Inglaterra compró los bonos egipcios en la Compañía del Canal y estableció una intervención acordada con Francia sobre las finanzas egipcias cuando Ismail cesó el pago de la deuda externa. Luego depusieron a Ismail y colocaron a su dócil hijo Tawfiq. Pero la brutal intervención provocó la revolución popular de Orabí Pachá, que concluyó con la invasión inglesa de 1882 y el establecimiento del protectorado británico hasta 1914.

Con la administración británica -cuya figura emblemática fue Lord Cromer (estrechamente ligado a la banca Baring)- se lograba el absoluto predominio de las finanzas inglesas sobre el mercado local de capitales. Respecto del agro, el protectorado impuso un sistema de irrigación perenne para las tierras algodoneras, el uso masivo de fertilizantes y la ampliación del área de cultivo en detrimento de los cereales (que se importan de América). Ello condujo a un agotamiento del suelo, enfermedades y malnutrición que afectaron a la mano de obra. Un segundo frente algodonero bajo control británico se estableció en Sudán, pero de modo muy lento: el espectacular triunfo del Mahdi en Jartum (1885) detuvo ese proceso y recién en 1898 se concretó la conquista anglo-egipcia.

\section{Reabriendo el debate}

Hasta aquí, hemos intentado mostrar algunos aspectos que desmienten el no tan riguroso 
argumento de Doratioto acerca del algodón egipcio y el alivio de la demanda británica. Dicho autor no ha tenido en cuenta que con Mehmet Said creció la exportación algodonera egipcia pero sin la inversión extranjera en los niveles esperados por la banca británica, dado que el gobierno egipcio se benefició con una coyuntura favorable de los precios, recurriendo al mercado local de capitales. Además, desconoce Doratioto que el proyecto de construcción del canal de Suez insumió un número muy importante de campesinos, es decir que compitió con el sector algodonero por la mano de obra, siendo ello contrario a los intereses británicos de contar con un algodón bueno, barato y abundante. Y algo más, Doratioto desconoce que la mecanización en las obras del canal recién comienzan al iniciarse la Guerra Guasú.

Finalmente, Inglaterra logró una afluencia algodonera en mejores condiciones recién con el establecimiento del protectorado en 1882, la generalización de la irrigación perenne y del uso de fertilizantes, el estrangulamiento del mercado local de capitales y -luego- la conquista del Sudán. Por otra parte, la industria de Lancashire no pudo procesar correctamente el algodón de fibra larga hasta fines del XIX y los precios internacionales del algodón, si bien bajaron tras el fin de la guerra civil norteamericana, mantuvo niveles elevados. Todos estos elementos prueban que Egipto no fue el apacible y blanco granero de Inglaterra capacitado para desalentar la búsqueda de nuevas zonas productoras de algodón barato.

Por el contrario, vemos que la Manchester Cotton Supply Association entre 1861-1863 (tras la batalla de Pavón y en los mismos años en que presionaba a Egipto para que acepte capitales británicos en la producción algodonera para bajar los precios) encargó al cónsul Thomas Hutchinson y al publicista y comerciante Michael Mulhall explorar las posibilidades algodoneras de Santiago del Estero, Corrientes y Paraguay, enviándoles semillas de algodón. Y si bien estos esfuerzos no prosperaron en lo inmediato $\mathrm{y}$ se focalizaron en Argentina, dieron sus frutos tiempo después en regiones arrebatadas al Paraguay tras la guerra (Guy, 1993: 100-104).
Podemos conjeturar, entonces, que justamente por esas dificultades en el mercado algodonero egipcio Gran Bretaña tenía mayor interés en abrir nuevos frentes algodoneros, como por ejemplo en la cuenca del Plata, donde la férrea política estatista del Paraguay se muestra como un obstáculo. Esto implicaría invertir la lógica del argumento de Doratioto.

\section{Conclusión}

Hay un consenso en torno a considerar que la apertura democrática en América Latina y las transformaciones en el campo académico de los últimos tiempos dieron oxigeno a la investigación histórica. Se señala nuevos temas y enfoques sobre la Guerra Guasú: la historia cultural, de la prensa, de género, etc. Se celebra que se aborden cuestiones tabúes (Brezzo, 2003). Pero el rol del imperialismo británico en la región queda condenado como tema del pasado, teñido de "política", indigno de interés académico. Renovar los métodos para indagar y comprender el rol de Inglaterra en el origen y decurso de la guerra creemos que es también romper con un moderno tabú, hijo de los prejuicios ideológicos.

A fin de cuentas, una de las consecuencias más significativas de esta guerra consistió en consolidar la conexión al mercado mundial capitalista en calidad de proveedoras de materias primas baratas las diversas áreas que componen la Cuenca del Plata.

Por otra parte, como creemos haber demostrado en este trabajo, la provisión egipcia no eliminó el interés británico por abrir nuevas zonas algodoneras incluso desde antes de la guerra. Incluso puede afirmarse que la pertinaz resistencia egipcia a amoldarse a las necesidades financieras y productivas del capital británico en materia algodonera, los altos precios, la competencia por la mano de obra y las limitaciones técnicas de Lancashire contribuyeron a hacer de Egipto no la coartada para explicar la estricta neutralidad británica en el conflicto bélico del Plata sino mas bien un estímulo para buscar nuevos mercados algodoneros. 
La reapertura de esta discusión nos parece de relevancia dado que involucra al proceso de gestación estatal argentino en confrontación con distintos proyectos político-sociales en la región. En momentos en que Argentina ve hipotecado su futuro por un cuestionado acuerdo con el Fondo Monetario Internacional, en que las voces del negacionismo justifican y añoran el terrorismo de Estado, y el gobierno se somete sin ambages a un alineamiento internacional con intereses ajenos a la región, descorrer el telón a la versión oficial del parto del Estado argentino es una tarea de la memoria de un pueblo que alumbra la búsqueda de salidas para sus luchas de la hora.

\section{Referencias bibliográficas}

al-Sayyid Marsot, Afaf Lufti. Egypt in the Reign of Muhammad Ali. Cambridge University Press, 1984.

A History of Egypt. From the Arab Conquest to the Present. Cambridge University Press.

Amin, Samir. La nation arabe. Nationalisme et luttes de classes. Paris, 1976.

Azaola Piazza, Bárbara. Historia del Egipto contemporáneo. Catarara Editor, Madrid, 2008.

Bethell, Leslie (Org.) A Guerra do Paraguai: 130 anos despois. Relume Dumará, Río de Janeiro, 1995.

Brezzo, Liliana. “La historiografía paraguaya: del aislamiento a la superación de la mediterraneidad", en Diálogos, DHI/UEM, v. 7, Maringá, 2003 (pp. 157-175).

Chiaradía, Esteban. "La Guerra de la Triple Alianza como sepulturera del ideal americanista en el ámbito sudamericano". XI Jornadas de Sociología. Facultad de Ciencias Sociales, Universidad de Buenos Aires, Buenos Aires, 2015.

Chiaradía, Esteban y Sacco, Claudio. “Egipto no alcanza y Paraguay promete. El algodón en el debate sobre las causas de la Guerra Guasú". En: Actas X Jornadas de Investigadores en Historia, UNMdP, Mar del Plata, 2014. ISBN 978_987_544_611_3

Chiavenato, Julio José. Genocidio Americano. La Guerra del Paraguay. Asunción: Carlos Schauman Editor, 1989 [1979].

Creydt, Oscar. Formación Histórica de la Nación Paraguaya. Asunción: s/ed., 1963.

Doratioto, Francisco. Maldita guerra. Nueva historia de la Guerra del Paraguay. Buenos Aires: Emece, 2008.

"História e Ideologia: a produção brasileira sobre a Guerra do Paraguai". En: Nuevo Mundo Mundos Nuevos, $\quad$ http://nuevomundo.revues. org/49012 (puesto en línea 13/01/2009, consultado 15/02/2014)

Fargette, Guy. Méhémet Ali. Le fondateur de l'Egypte moderne, Éditions L'Harmattan, París, 1996.

Fornos Peñalba, José Alfredo. The Fourth Ally. Great Britain and the War of the Triple Alliance. Los Ángeles: University of California Press, 1979.

Galeano, Eduardo. Las venas abiertas de América Latina. Editorial Arte y Literatura, 1971.

Guerra Vilaboy, Sergio. Paraguay: de la independencia a la dominación imperialista. 1811-1870. La Habana: Editorial de Ciencias Sociales, 1984.

Guy, Donna. “Oro blanco: algodón, tecnología y mano de obra familiar en la Argentina del siglo XIX". En Boletín del Instituto Ravignani, 3ra serie, $n^{\circ}$ 7, Buenos Aires, 1993.

Headrick, Daniel. Los instrumentos del Imperio. Tecnología e Imperialismo europeo en el siglo XIX, Altaya, Madrid, 1998. 
Maestri, Mario (2009). "A Guerra Contra o Paraguai: História e Historiografia: Da instauração à restauração historiográfica [1871-2002]". En: Estudios Historicos, CDHRP, Agosto 2009, № 2, ISSN: 1688 5317.

Menezes, Alfredo da Mota. A guerra é nossa: a Inglaterra não provocou a Guerra do Paraguai. São Paulo: Editora Contexto (Editora Pinsky Ltda.), 2012.

Moniz Bandeira, Luiz Alberto. O Expansionismo Brasileiro: o papel do Brasil na Bacia do Prata. Da colonização ao Império. Rio de Janeiro: Philobiblion, 1985.

Morgenfeld, Leandro. Vecinos en conflicto. Argentina y Estados Unidos en las Conferencias Panamericanas (1880-1955). Buenos Aires: Peña Lillo - Continente, 2011.

Ortega Peña, Rodolfo y Duhalde, Eduardo. Felipe Varela contra el Imperio Británico. Buenos Aires: Shapire, 1975.

Pomer, León. La Guerra del Paraguay. Estado, política y negocios. Buenos Aires: Centro Editor de América Latina, 1968. argentina (1865 - 1870). Buenos Aires. Amorrortu, 1986.

Quintana Pali, Santiago. “El algodón en Egipto, 1805-1930", en Revista Estudios de Asia y África, XVI: 3, El Colegio de México, México, 1981 (pp. 436-465).

Rivera, Enrique. José Hernández y la Guerra del Paraguay. Buenos Aires: Indoamérica, 1954.
Rogan, Eugene. Los árabes. Del imperio otomano a la actualidad, Crítica Editorial, Madrid, 2010.

Romero, Luis Alberto. "La historiografía argentina en la democracia: los problemas de la construcción de un campo profesional", en: Entrepasados, Revista de Historia, año VI, N 10, Buenos Aires, 1996.

Rosa, José María. La Guerra del Paraguay y las montoneras argentinas. Buenos Aires: Peña Lillo, 1965.

Sales, Thiago Rabelo. "Guerra do Paraguai: Controvérsias da Historiografia sobre as causas do conflito". En: Anais do I Encontro Memorial do ICHS, noviembre de 2004. En línea: http://www.ichs.ufop.br/memorial/ trab/h9_2.pdf (consulta: 01/04/2015).

Salles, Ricardo. Guerra do Paraguai, escravidão e cidadania na formação do exército. Rio de Janeiro: Paz e Terra, 1990.

Scalabrini Ortíz, Raúl. "Defensa retrospectiva de una coima de un millón de dólares" en Revista Qué, Buenos Aires: 30/10/1956.

Tate, E. N. “Gran Bretaña y Latinoamérica en el siglo XIX: el caso de Paraguay, 1811-1870". En: Contribuciones desde Coatepec, núm. 5. México: Universidad Autónoma del Estado de México, 2003 (pp. 67-98)

Trías, Vivian. El Paraguay. De Francia el Supremo a la Guerra de la Triple Alianza. Bs. As.: Crisis, 1975. 


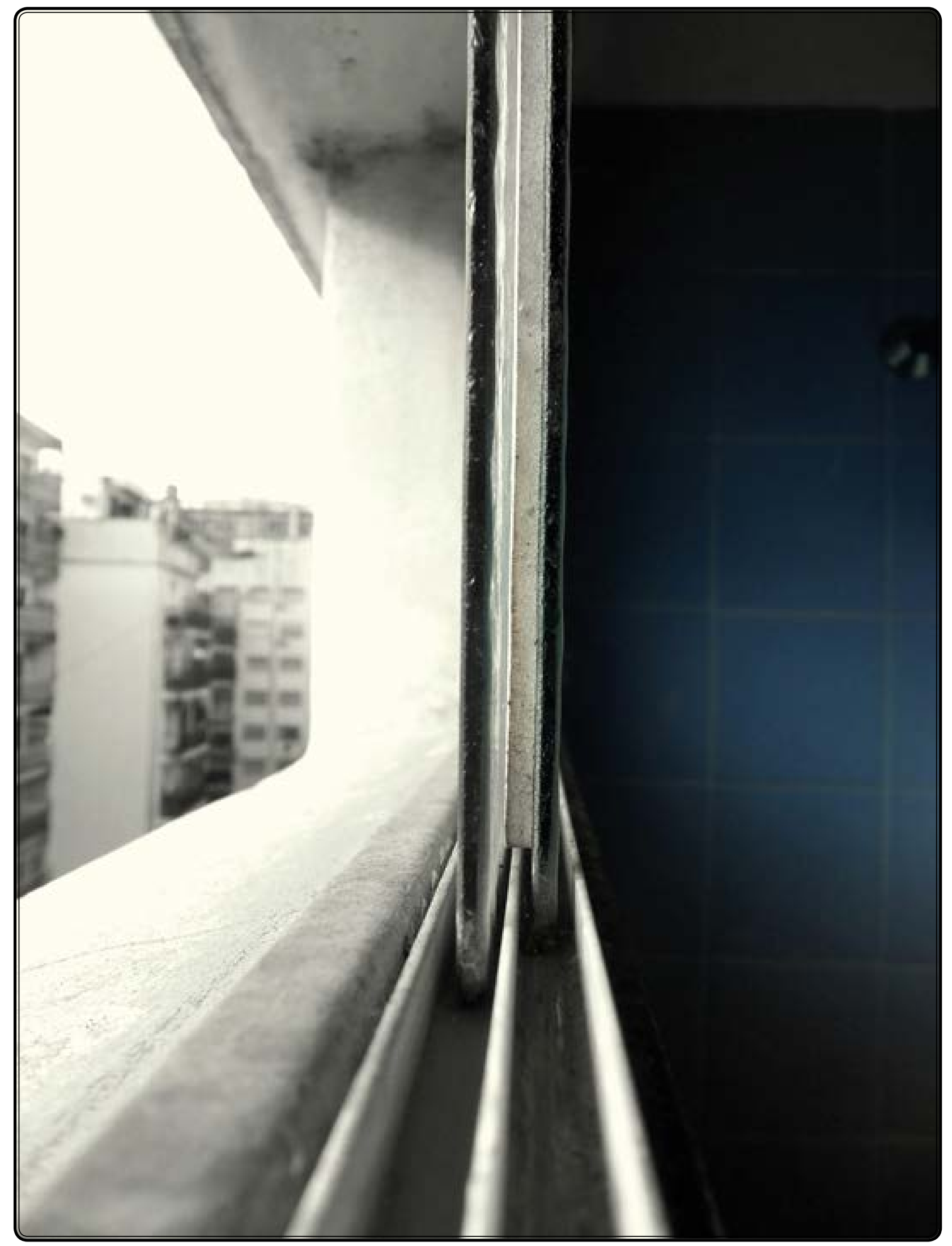

Bostezos de una ciudad sin cielo. 